\title{
Effect of Temperature on Host Preference in Two Lineages of the Brown Dog Tick, Rhipicephalus sanguineus
}

\author{
Laura H. Backus, ${ }^{*}$ Andrés M. López Pérez, and Janet E. Foley \\ Department of Medicine and Epidemiology, School of Veterinary Medicine, University of California, Davis, Davis, California
}

\begin{abstract}
Rhipicephalus sanguineus is a species complex of ticks that vector disease worldwide. Feeding primarily on dogs, members of the complex also feed incidentally on humans, potentially transmitting disease agents such as Rickettsia rickettsii, Rickettsia conorii, and Ehrlichia species. There are two genetic Rh. sanguineus lineages in North America, designated as the temperate and tropical lineages, which had occurred in discrete locations, although there is now range overlap in parts of California and Arizona. Rh. sanguineus in Europe are reportedly more aggressive toward humans during hot weather, increasing the risk of pathogen transmission to humans. The aim of this study was to assess the impact of hot weather on choice between humans and dog hosts among tropical and temperate lineage $R h$. sanguineus individuals. Ticks in a two-choice olfactometer migrated toward a dog or human in trials at room $\left(23.5^{\circ} \mathrm{C}\right)$ or high temperature $\left(38^{\circ} \mathrm{C}\right)$. At $38^{\circ} \mathrm{C}, 2.5$ times more tropical lineage adults chose humans compared with room temperature, whereas temperate lineage adults demonstrated a $66 \%$ reduction in preference for dogs and a slight increase in preference for humans. Fewer nymphs chose either host at $38^{\circ} \mathrm{C}$ than at room temperature in both lineages. These results demonstrate that risk of disease transmission to humans may be increased during periods of hot weather, where either lineage is present, and that hot weather events associated with climatic change may result in more frequent rickettsial disease outbreaks.
\end{abstract}

\section{INTRODUCTION}

The Rhipicephalus sanguineus complex comprises $R h$. sanguineus sensu stricto (s.s.) as well as a group of morphologically and biologically similar ticks designated as $R h$. sanguineus sensu lato (s.l.). ${ }^{1}$ The two lineages of $R h$. sanguineus in North America have been designated as "temperate" and "tropical" lineages. ${ }^{2}$ Although the taxonomic status of the complex is not fully resolved, the temperate lineage is well defined molecularly and corresponds to the $R h$. sanguineus sensu stricto (s.s.) species, whereas a separate phylogenetic branch contains ticks in the tropical lineage and several other Rhipicephalus entities. ${ }^{1}$ Both tropical and temperate lineage ticks are competent vectors for zoonotic pathogens, including Ehrlichia canis, Ehrlichia chaffeensis, Ehrlichia ewingii, Coxiella burnetii, and numerous spotted fever group rickettsias-notably, Rickettsia rickettsii, R. conorii, and R. massiliae. ${ }^{37}$ In North America, the temperate lineage was associated with an outbreak of Rocky Mountain spotted fever (RMSF) caused by R. rickettsii in Arizona in 2004, ${ }^{6}$ whereas the tropical lineage has been implicated in ongoing outbreaks in Baja California Norte and Sonora, Mexico. ${ }^{8-10}$

All members of the $R h$. sanguineus complex are endophilic and monotropic (all stages tend to feed on dogs), with incidental feeding on humans and other mammalian hosts. ${ }^{11-15}$ Historically, however, the temperate and tropical lineages have occupied separate ranges in North America, with the distribution likely influenced by local climate. ${ }^{16}$ Globally, the tropical lineage is found where annual mean temperature exceeds $20^{\circ} \mathrm{C}$, whereas the temperate lineage is restricted to mean temperatures below that. ${ }^{2}$ Specific lineage adaptations likely drive the disparate distributions; for example, the temperate lineage has greater molt success at lower temperatures than the tropical lineage. ${ }^{17}$ In North America, the tropical lineage is present across the far southern portions of the United States. ${ }^{16}$ However, areas of overlap between the

*Address correspondence to Laura H. Backus, Department of Medicine and Epidemiology, School of Veterinary Medicine, University of California, Davis, 1320 Tupper Hall, Davis, CA 95616. E-mail: Ihbackus@ucdavis.edu temperate and tropical lineages occur in both Southern California and Arizona, with evidence that the tropical lineage is moving progressively northward at the margins of its range in these areas. ${ }^{10,18}$

Beyond ecological characteristics associated with the presence and survival, comparisons of behavior and vector competence between the tropical and temperate lineages are limited. Although both lineages are competent vectors, changes in the distribution of lineages, with differential survival and behavior under different climatic conditions, may result in changing patterns of rickettsial disease. Host attraction and feeding preferences are critical components of the eco-epidemiology of tick-borne disease. A network of preferred and pathogen-competent hosts is required to maintain an arthropod-borne pathogen within a system, and transmission of a pathogen is determined by the arthropod's host preferences as well as host availability. ${ }^{19,20}$ Host preference and tick attachment are influenced by host factors (e.g., presence/ absence of hosts, host behavior, and physical and chemical signals from hosts) and environmental off-host factors (e.g., climatic conditions and presence of microhabitat). ${ }^{21-23}$ Shifts in host preference could affect feeding frequency and pathogen maintenance and disease spillover into alternate hosts. ${ }^{19}$

There is evidence that $R h$. sanguineus may be more aggressive toward human hosts at increased ambient temperatures. ${ }^{7}$ Attachment and initiation of feeding also occur more rapidly at high temperatures. ${ }^{24}$ Higher temperatures and lower humidity are associated with greater aggression (increased host-seeking behavior or biting rate) in Ixodes persulcatus, and Ixodes scapularis host choice is influenced by humidity. ${ }^{25,26}$ Rickettsial disease emergence and reports of increased $R h$. sanguineus aggression during heat waves in Europe may be due to an increased proportion of ticks feeding on humans compared with dogs, an absolute increase in aggression, or a combination. ${ }^{7,27}$ The annual number of days over $38^{\circ} \mathrm{C}\left(100^{\circ} \mathrm{F}\right)$ is expected to increase markedly across most of the continental United States in next decade, ${ }^{28}$ increasing concern for heat-driven emergence of tick-borne disease. The aim of this study was to quantify differences in host preference and the effect of high ambient temperatures on host choice in two 
North American Rh. sanguineus lineages to determine whether climate and changes in lineage distribution may contribute to changing disease patterns.

\section{MATERIALS AND METHODS}

Tick sources and colony maintenance. Engorged adult female tropical lineage $R h$. sanguineus s.l. were collected from dogs who were infested on arrival at an animal shelter facility near Maricopa, Arizona, USA, and temperate lineage larvae were obtained from the colony maintained at Oklahoma State University. Partial sequencing of the 16 s ribosomal subunit was performed on a subset of females after oviposition ${ }^{29}$ and GenBank Blast search was performed to confirm conspecificity with the tropical lineage. Both lineages were reared concurrently and maintained at 85-95\% humidity with a 12-hour light/dark cycle. Approximately 80 days post-eclosure, larvae of both lineages were simultaneously fed on New Zealand white rabbits (Charles River Laboratories, Wilmington, MA) and permitted to molt. Behavior trials using nymphs were performed between 40 and 50 days post-molt. Nymphs were fed on naive New Zealand white rabbits approximately 60 days post-molt. Adults resulting from fed nymphs were used in trials $40-50$ days post-molt.

Olfactometer design. A two-choice olfactometer was designed and constructed to conduct behavior trials, with design adapted from published olfactometer studies. ${ }^{30,31}$ Two wooden boxes $(91 \times 76 \times 122 \mathrm{~cm})$ with rear hinge-attached access doors were connected with a $122-\mathrm{cm}$ long, $6.35-\mathrm{cm}$ diameter polyethylene terephthalate glycol plastic heavy wall tubing (see Figure 1). A small fan was placed in each box to facilitate air flow. The center tube was marked on both sides at $30.5 \mathrm{~cm}$ and $45 \mathrm{~cm}$ from the midpoint, and a capped tube was inserted at the midpoint to allow tick placement. Fabric mesh was used to confine ticks to the center tube and prevent access to the human or dog. Ambient temperature was controlled by placing the center tube in a large Styrofoam cooler and heating the surrounding air with two household electric fan-powered space heaters for hightemperature trials. Temperatures were recorded at the start of each trial and monitored continuously using a digital thermometer adjacent to the tubing.

Behavior trials. For nymphs, five trials for each lineage were performed at each temperature $\left(23.5 \pm 1{ }^{\circ} \mathrm{C}\right.$ and $38 \pm$ $2.5^{\circ} \mathrm{C}$ ) for 20 trial iterations and 800 total ticks tested. Ambient humidity ranged from $10 \%$ to $42 \%$ in $23.5^{\circ} \mathrm{C}$ trials and $10-35 \%$ in $38^{\circ} \mathrm{C}$ trials. For adults, 10 trials (five of each sex) were performed at each temperature for a total of 40 trial iterations and 800 ticks tested. Ticks used in the high temperature trials were held for at least 6 hours at $40^{\circ} \mathrm{C}$ and 80-90\% relative humidity before testing.

For each trial, a dog occupied one box and a human the other box, with 10 minutes elapsed before starting the trial to allow accumulation of scent and carbon dioxide. All dogs were neutered or spayed and midsize (15-30 kg) owned pets with owner consent. For nymphs, five trials were conducted for each temperature/lineage combination, with 10 combinations of dogs and humans used (eight humans and five dogs). For adults, 10 trials (five each for male and female ticks) were conducted for each temperature/lineage combination, with six combinations of dogs and humans used (four humans and three dogs).

Ticks were deposited at the midpoint at the tube. For nymphs, 40 ticks of a single lineage were used for each trial. Trials of adult ticks were performed in groups of 20 of a single sex. Trials were performed for 20 minutes past the time ticks were placed in the tube. Every 2 minutes, the number of ticks in each section was counted. Ticks moving beyond $30.5 \mathrm{~cm}$ (nymphs) or $45 \mathrm{~cm}$ (adults) from the midpoint were considered to have demonstrated preference at that time point, but were free to move backward and forward.

Data analysis. Data were managed and analyzed in $R(R$ Foundation for Statistical Computing, Vienna, Austria). Separate log-binomial mixed-effect generalized linear models were used for each stage to compare the effects of temperature on host choice using the "Ime4" package in R. ${ }^{32}$ Separate models were used for overall host choice, human host choice, and dog host choice. Tick choice for human, dog, or both was used as the dependent variable, temperature and lineage used as independent variables, and tick sex (for adult ticks) and interaction between temperature and lineage considered as additional predictors. The dog-human combination used for the trial was included as a random intercept. Temperature and lineage were both included as binary variables, with room temperature and tropical lineage used as reference. Individual model effect estimates were considered significant if $P<0.05$ when compared with the reference value, and relative risks (RRs) calculated from the model were considered significant when the $95 \%$ Wald $\mathrm{Cl}$ did not include 1 .

\section{RESULTS}

The two lineages varied markedly in their preference for humans versus dogs at room temperature. At room temperature, the temperate lineage showed greater preference for

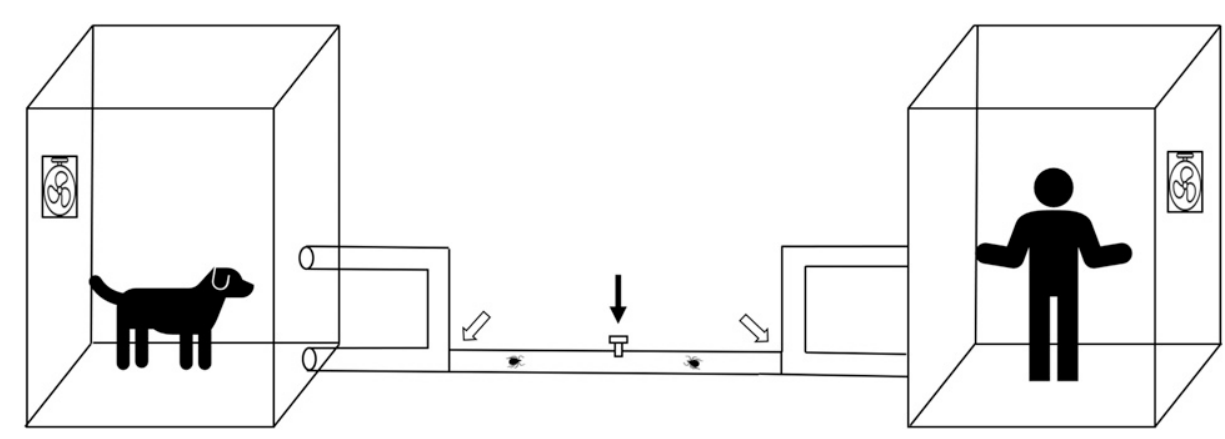

FIGURE 1. Diagram of olfactometer for assessment of host preference between a dog and human in ticks. Ticks are inserted at the center point of the middle tube (solid arrow) and prevented from accessing human or dog by a fabric mesh (hollow arrows). A fan in each box facilitates air flow into the tubing. The center tube (between hollow arrows) measures $122 \mathrm{~cm}$ in length, and each box measures $91 \times 76 \times 122 \mathrm{~cm}$. 
humans over dogs than the tropical lineage, with nearly twice as many temperate nymphs and 2.2 times more temperate adults choosing the human than the tropical lineage (Table 1).

High temperatures suppressed host choice in nymphs in both lineages, with fewer nymphs choosing any host at high temperatures, although the effect was nonsignificant in the temperate lineage (Figure 2). In tropical lineage nymphs, high temperature reduced the probability of ticks choosing either host by $43 \%$ (RR: $0.57,95 \% \mathrm{Cl}: 0.35-0.92$ ), a reduction primarily due to fewer ticks choosing dogs (RR: $0.27,95 \% \mathrm{Cl}$ : 0.09-0.82), whereas the probability of a nymph choosing the human was unchanged (RR: 1.02, 95\% Cl: 0.54-1.89).

The effect of heat on host choice in adults differed significantly by lineage for human, dog, and overall host choice, with a greater effect observed in the tropical lineage as shown by the significant interaction between lineage and temperature (Table 2). Tick sex was not significant in any of the host choice models, and so was dropped from further analysis. In temperate lineage adults, overall host choice was not significantly different between room and high temperature, but there was a relative shift in preference for the human over dog, with a $66 \%$ decrease in the risk of a tick choosing a dog (RR: $0.34,95 \% \mathrm{Cl}$ : 0.19-0.57) and a small but not significant increase in the risk of choosing a human (RR: $1.22,95 \% \mathrm{Cl}$ from 0.93 to 1.60 ). In the tropical lineage, high temperature increased the mean number of ticks choosing a host, which occurred primarily because of an increased preference for humans, with the risk of a tick choosing the human being 2.5 times greater at high temperature than at room temperature $(95 \% \mathrm{Cl}: 1.71-3.65)$; the probability of a tick choosing the dog did not change significantly.

\section{DISCUSSION}

In the first experiment to quantify the effect of temperature on host preference in $R h$. sanguineus, we show that there is an increased risk of humans being bitten by adult ticks as temperatures increase. In temperate lineage $R h$. sanguineus, high temperatures increased the relative preference of humans over dogs (a similar number of ticks made a host choice at each temperature, but a greater proportion selected the human), whereas in the tropical lineage, high temperatures increased the total number of ticks choosing humans. Although it has been noted in multiple tick species that host aggression in general is higher under hot weather conditions, ${ }^{7,26}$ these findings demonstrate that relative preference may also increase at high temperatures, so preference is increased more for one host than another. These findings suggest that changing climate may increase human bites and subsequent pathogen transmission, particularly in areas occupied by the tropical lineage. Expansion of the tropical lineage may result in climatic or weather events being stronger drivers of disease emergence in these areas, or overall increased risk of human disease, especially if the temperate lineage is not displaced.

In nymphs, there appears to be a smaller shift during increasing temperature toward relative preference for humans than was observed in adults, although the host drive decreased overall at higher temperatures. This is in contrast to the observation that attachment to humans occurs in greater numbers and more rapidly in nymphal $R h$. sanguineus that are held at higher temperatures than at room temperature. ${ }^{7}$ High temperatures may therefore suppress nymphal hunting or ambush behaviors while simultaneously increasing how rapidly they attach to a host as mechanism to allow nymphs to survive in environments where temperatures exceed our experimental conditions. ${ }^{2,6}$ Unfed $R h$. sanguineus nymphs are much more sensitive to heat and desiccation than adults, ${ }^{33}$ so it is possible that host seeking was impaired under hot conditions. Drop-off of engorged nymphs and adult females tends to occur at night, ${ }^{34}$ but the hunting behavior of nymphs in the environment has not been well described.

Experimental and surveillance studies suggest that typically a very small percentage of $R h$. sanguineus attach to human hosts, ${ }^{35,36}$ and olfactory preference rather than attachment was measured here. However, surveys of ticks feeding on humans have reported instances of human parasitism by both the temperate and tropical lineages around the world, suggesting that feeding on humans by $R h$. sanguineus may be under-recognized. ${ }^{37-40}$ Temporal and spatial clustering of human parasitism events have also been described, again in both lineages and with a broad geographic distribution in the Americas and Europe. $7,12,41,42$ Clusters of human parasitism are less likely to be detected if not associated with cases of disease, but their occurrence suggests that there are forces driving $R h$. sanguineus in these instances to feed on humans with increasing intensity that may be related to either tick behavior or focus of high density.

Genetic shifts in populations have been postulated to play a role in increased human parasitism. ${ }^{12}$ Because groups within the sensu lato complex are morphologically similar or

TABle 1

Mean and SD of number of Rhipicephalus sanguineus ticks selecting dog or human per trial at room $\left(23.5^{\circ} \mathrm{C}\right)$ and high $\left(38^{\circ} \mathrm{C}\right)$ temperatures

\begin{tabular}{|c|c|c|c|c|}
\hline Nymphs & Room temperature & High temperature & $T$ & $P$-value \\
\hline \multicolumn{5}{|l|}{ Temperate lineage } \\
\hline Mean \#choosing dog \pm SD (\%) & $1.4 \pm 1.7(3.7)$ & $1.0 \pm 2.2(2.6)$ & -0.32 & 0.758 \\
\hline Mean \#choosing human \pm SD $(\%)$ & $9.2 \pm 3.3(23.7)$ & $7.8 \pm 5.9(20.2)$ & -0.46 & 0.658 \\
\hline \multicolumn{5}{|l|}{ Tropical lineage } \\
\hline Mean \#choosing dog \pm SD (\%) & $8.4 \pm 3.6(21.9)$ & $2.8 \pm 2.7(7.1)$ & -2.77 & 0.027 \\
\hline Mean \#choosing human \pm SD $(\%)$ & $5.2 \pm 3.7(13.8)$ & $5.6 \pm 2.4(14.4)$ & 0.20 & 0.845 \\
\hline Adults & Room temperature & High temperature & $T$ & $P$-value \\
\hline \multicolumn{5}{|l|}{ Temperate lineage } \\
\hline Mean \#choosing dog \pm SD (\%) & $4.9 \pm 3.3(25.8)$ & $1.6 \pm 1.4(8.2)$ & -2.92 & 0.013 \\
\hline Mean \#choosing human \pm SD $(\%)$ & $6.5 \pm 3.8(33.7)$ & $7.9 \pm 2.8(41.2)$ & 0.94 & 0.361 \\
\hline \multicolumn{5}{|l|}{ Tropical lineage } \\
\hline Mean \#choosing dog \pm SD (\%) & $5.2 \pm 2.5(22.5)$ & $4.4 \pm 2.3(25.3)$ & 0.74 & 0.471 \\
\hline Mean \#choosing human \pm SD (\%) & $2.9 \pm 2.5(14.8)$ & $7.5 \pm 4.1(37.4)$ & 3.03 & 0.009 \\
\hline
\end{tabular}




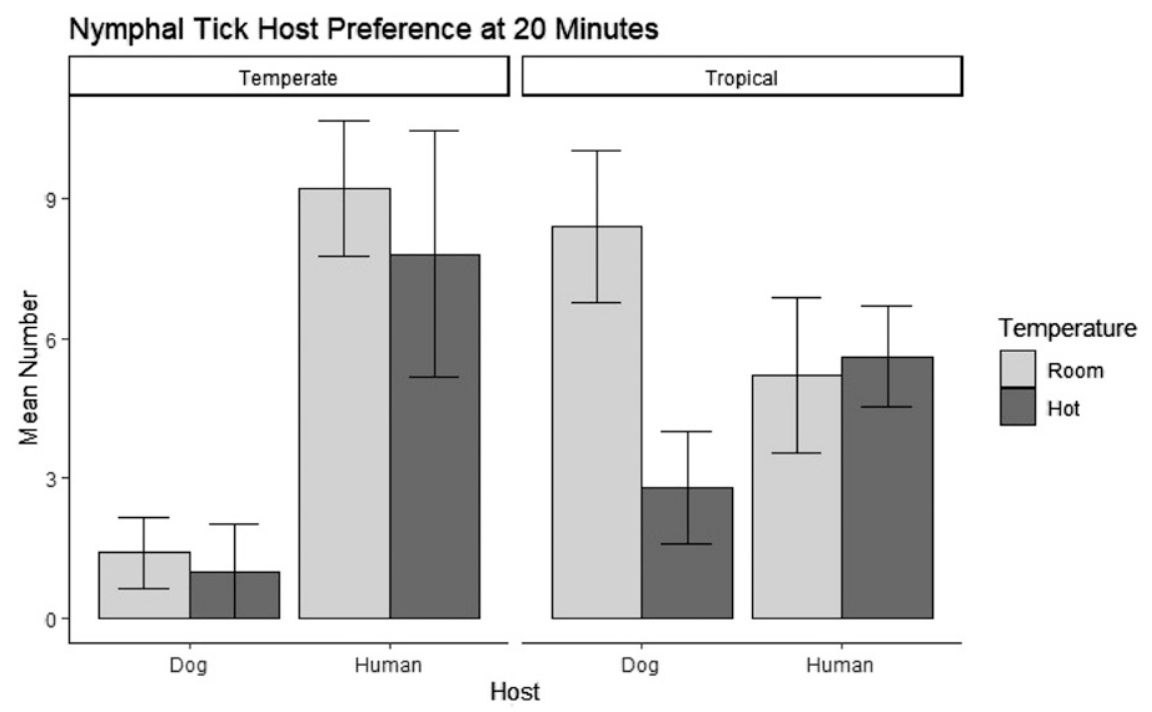

Adult Tick Host Preference at 20 Minutes

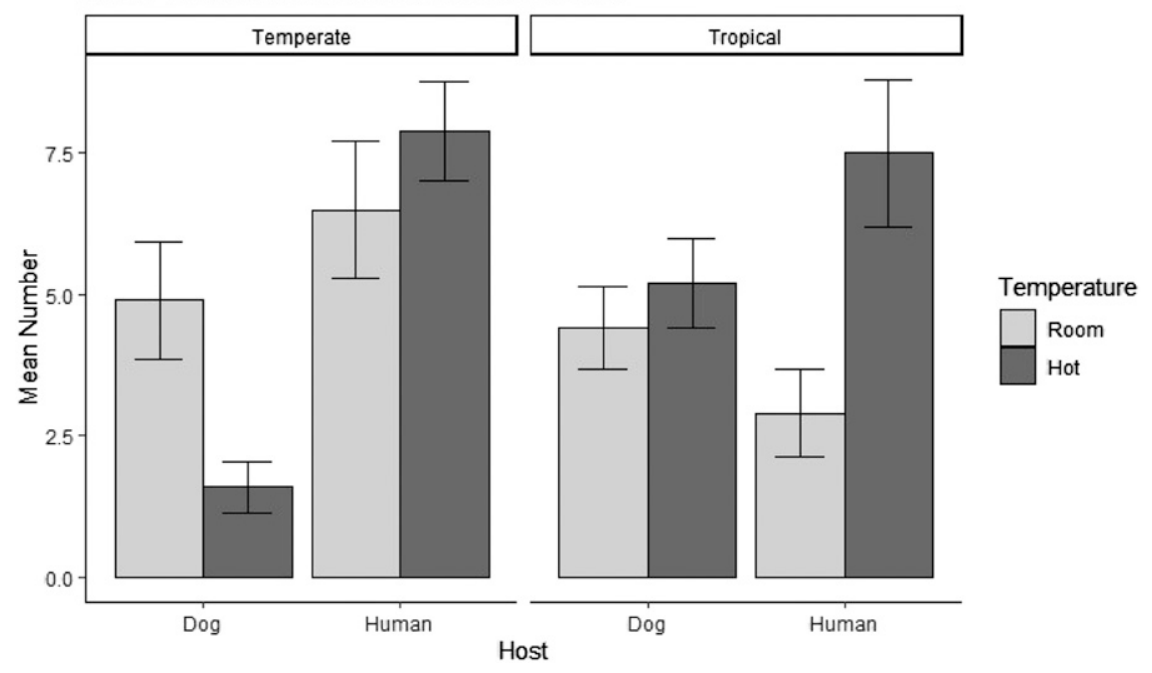

FIGURE 2. Mean number of ticks $( \pm \mathrm{SD})$ of temperate and tropical lineage choosing dog or human at room temperature $\left(23^{\circ} \mathrm{C}\right)$ or high temperature $\left(38^{\circ} \mathrm{C}\right)$. Nymph trials were performed with 40 ticks, and adult trials were performed with 20 ticks.

indistinguishable, invasion or expansion of other $R h$. sanguineus lineages may occur undetected. ${ }^{10,43,44}$ If the invading genotype differs in its behavior or vectoral capacity, a subsequent shift in human parasitism or disease transmission could be expected. The results of this experiment, however, demonstrate that behavioral changes due to environmental factors may be at least partially responsible for clusters of human parasitism and that epidemic transmission could be driven by weather events and climatic patterns.

The finding that high temperatures drive human parasitism is further supported by the relationship between rickettsial disease cases caused by $R h$. sanguineus and weather events. Mediterranean spotted fever, caused by $R$. conorii, is also vectored by $R h$. sanguineus, and cases in Europe have been correlated repeatedly with periods of higher temperature. ${ }^{45,46}$ In France in 2007 , spring temperatures $3-4^{\circ} \mathrm{C}$ above normal (greater than $25^{\circ} \mathrm{C}$ ) were associated with both observed intense human parasitism and rickettsial disease cases. ${ }^{7}$ All life stages of $R h$. sanguineus feed most frequently in the summer and fall, ${ }^{47}$ which is also when RMSF cases in the United States are most frequently reported, ${ }^{6,48}$ although correlation between unusually hot weather events and specific cases or outbreaks has not been described. In Arizona, cases including the eastern Arizona epidemic display an extended seasonality, with cases reported into December, indicating a shift in tick activity. ${ }^{49,50}$ Across the United States, temperatures greater than $35^{\circ} \mathrm{C}$ are associated with cases of spotted fever rickettsiosis, although many of these are vectored by Dermacentor variabilis. ${ }^{51}$ Taken together, these findings warrant further investigation into both transient weather events and climatic trends as predictors of RMSF cases. In light of the experimental results here, the magnitude of effect on changes in human biting rates may depend on the particular population and lineage of $R h$. sanguineus, although shifts away from dogs and toward humans may occur in areas where either lineage is present.

The finding that the temperate lineage had markedly higher preference for humans at room temperature was unexpected. However, some of the variation in baseline preferences between the tropical and temperate lineages may be attributable 


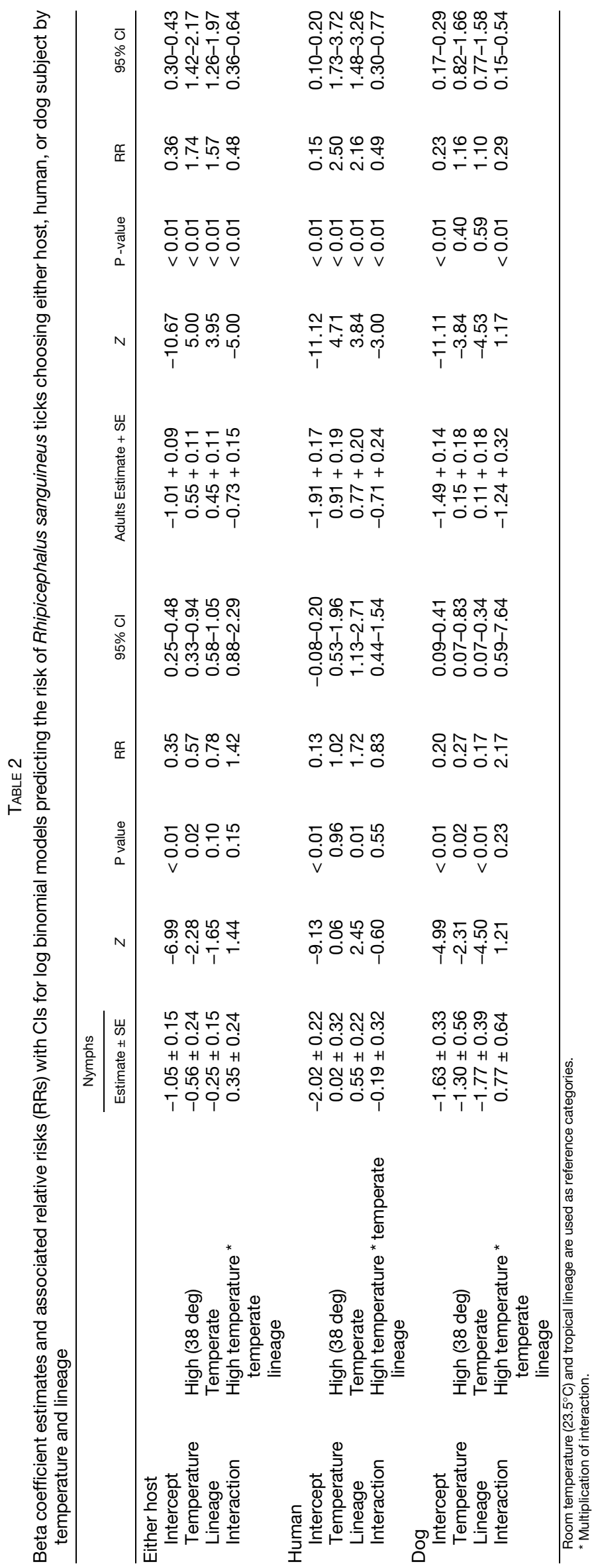


to the tick origins. The temperate lineage was obtained from colony-maintained ticks, which may have affected the hostseeking behavior through selection for feeding on rabbits over multiple generations, whereas the tropical lineage originated from wild-caught ticks feeding on dogs. This highlights a concern about the use of colony-raised ticks for behavioral and life history studies and suggests that caution is warranted in extrapolating results from colony-raised to wild ticks. In addition, variation may not be strictly due to genetic lineage, as local populations of the same species of tick may show different behavioral characteristics, as is the case for I. scapularis. ${ }^{52}$

This study was performed comparing only two temperatures, and further experiments are warranted to test lower temperatures (below $23^{\circ} \mathrm{C}$ ), at gradations between the temperatures used here, and higher temperatures to determine whether host preference varies linearly with temperature or whether there is a threshold effect. Although this study shows that there is a shift in preference at hot temperatures, it does not quantify the change in the number of bites that is expected to occur, and further research is needed to provide these data across the spectrum of environmental conditions expected to occur. The chemical or physiologic basis for host preference is driven by a number of mechanisms, not all of which are well understood in $R h$. sanguineus ticks. The design of the twodirection olfactometer using actual hosts was intended to capture the cumulative effects of each of these factors and better replicate the conditions produced when ticks are host-seeking in the environment, where perception of two hosts may happen simultaneously, with ticks able to change direction as they get closer to a host. Ticks are attracted to hosts by chemical signals (host pheromones or kairomones), heat or infrared light, ${ }^{53}$ and, in some cases, visual and auditory cues. ${ }^{54,55}$ Carbon dioxide produced by host respiration is attractive to ticks across species, with the gradient likely used for host localization, ${ }^{56}$ and $R h$. sanguineus specifically are responsive to ammonia. ${ }^{22}$ These factors may vary between demographic groups of both dogs and humans. ${ }^{57,58}$ Comparing a wider variety of dog breeds and sizes with more demographic variation of the humans, including children, would allow more refinement of the risk to humans at high temperatures.

From these results, we conclude that short-term weather patterns and climatic change may both impact the transmission of pathogens transmitted by $R h$. sanguineus to humans. It is difficult to directly correlate large-scale climatic effects on the expansion of ticks and emergence of tick-borne diseases, ${ }^{59}$ but these results suggest that even short-term weather events may significantly affect disease transmission to humans and provide evidence that increased caution and tick protection are warranted under hot weather conditions. Hot weather events may be predictive of increased cases of $R h$. sanguineus-borne zoonotic disease, particularly in areas where the sensu lato group may be present; range expansion of the tropical lineage with concurrent climatic changes may significantly alter pathogen transmission patterns in those areas. These results also highlight the importance of further and ongoing work to describe the changing distribution of the different lineages within the $R h$. sanguineus complex in North America.

Received October 21, 2020. Accepted for publication February 28, 2021.

Published online April 5, 2021.

Acknowledgments: We would like to acknowledge the multitude of supporters who made this research possible, including Michael Levin and the CDC Medical Entomology Laboratory for invaluable training and advice; Maureen Brophy for collecting and sending ticks; and our human and dog volunteers: Emily Pascoe, Matteo Marcantonio, Jessica Sanchez, Nadia Javeed, Jill Huynh, Paola Vidal, Stephanie Castle, Scott Somerville, Sadie Trombley, Laura Shultz, Cassidy, Aska, Tazi, Louis, and Andy.

Financial support: This research was funded through support of the Pacific Southwest Regional Center of Excellence for Vector-Borne Diseases, funded by the U.S. Centers for Disease Control and Prevention (Cooperative agreement 1U01CK000516).

Authors' addresses: Laura H. Backus, Andrés M. López Pérez, and Janet E. Foley, Department of Medicine and Epidemiology, School of Veterinary Medicine, University of California, Davis, Davis, CA, E-mails: Inbackus@ucdavis.edu, amlope@ucdavis.edu, and jefoley@ ucdavis.edu.

\section{REFERENCES}

1. Nava S et al., 2018. Rhipicephalus sanguineus (Latreille, 1806): neotype designation, morphological re-description of all parasitic stages and molecular characterization. Ticks Tick-borne Dis 9: 1573-1585.

2. Zemtsova GE, Apanaskevich DA, Reeves WK, Hahn M, Snellgrove A, Levin ML, 2016. Phylogeography of Rhipicephalus sanguineus sensu lato and its relationships with climatic factors. Exp Appl Acarol 69: 191-203.

3. Murphy GL, Ewing SA, Whitworth LC, Fox JC, Kocan AA, 1998. A molecular and serologic survey of Ehrlichia canis, E. chaffeensis, and $E$. ewingii in dogs and ticks from Oklahoma. Vet Parasitol 79: 325-339.

4. Stoffel RT et al., 2014. Experimental infection of Rhipicephalus sanguineus with Ehrlichia chaffeensis. Vet Microbiol 172: 334-338.

5. Rovery C, Brouqui P, Raoult D, 2008. Questions on Mediterranean spotted fever a century after its discovery. Emerg Infect Dis 14: 1360-1367.

6. Demma LJ et al., 2005. Rocky Mountain spotted fever from an unexpected tick vector in Arizona. N Engl J Med 353: 587-594.

7. Parola P, Socolovschi C, Jeanjean L, Bitam I, Fournier PE, Sotto A, Labauge P, Raoult D, 2008. Warmer weather linked to tick attack and emergence of severe rickettsioses. PLoS Negl Trop Dis 2: e338.

8. Álvarez-Hernández G, Roldán JFG, Milan NSH, Lash RR, Behravesh CB, Paddock CD, 2017. Rocky Mountain spotted fever in Mexico: past, present, and future. Lancet Infect Dis 17: e189-e196.

9. Eremeeva ME et al., 2011. Rickettsia rickettsii in Rhipicephalus ticks, Mexicali, Mexico. J Med Entomol 48: 418-421.

10. Villarreal Z, Stephenson N, Foley J, 2018. Possible northward introgression of a tropical lineage of Rhipicephalus sanguineus ticks at a site of emerging Rocky Mountain spotted fever. J Parasitol 104: 240-245.

11. Dantas-Torres F, Figueredo LA, Brandão-Filho SP, 2006. Rhipicephalus sanguineus (Acari: ixodidae), the brown dog tick, parasitizing humans in Brazil. Rev Soc Bras Med Trop 39: 64-67.

12. Goddard J, 1989. Focus of human parasitism by the brown dog tick, Rhipicephalus sanguineus (Acari: ixodidae). $J$ Med Entomol 26: 628-631.

13. Walker J, Keirans J, Horak I, 2000. The Genus Rhipicephalus (Acari, Ixodidae): A Guide to the Brown Ticks of the World. Cambridge, England: Cambridge University Press.

14. Rhodes AR, Norment BR, 1979. Hosts of Rhipicephalus sanguineus (Acari: ixodidae) in northern Mississippi, USA. J Med Entomol 16: 488-492.

15. Martins TF, Reis JL, Viana EB, Luz HR, Oda FH, Dantas SP, Labruna MB, 2020. Ticks (Acari: ixodidae) on captive and freeranging wild animals in Tocantins state, a cerrado-amazon transition region of northern Brazil. Int J Acarol 46: 254-257.

16. Jones EO, Gruntmeir JM, Hamer SA, Little SE, 2017. Temperate and tropical lineages of brown dog ticks in North America. Vet Parasitol Reg Stud Rep 7: 58-61.

17. Labruna MB, Gerardi M, Krawczak FS, Moraes-Filho J, 2017. Comparative biology of the tropical and temperate species of 
Rhipicephalus sanguineus sensu lato (Acari: ixodidae) under different laboratory conditions. Ticks Tick-borne Dis 8: 146-156.

18. Schaefer C, Allen J, Yao T, Owen H, Lisowski S, VandenBrooks J, 2019. The phylogenetics of Rhipicephalus sanguineus and its role as a vector of Rocky Mountain spotted fever. FASEB J 33: lb296.

19. Simpson JE, Hurtado PJ, Medlock J, Molaei G, Andreadis TG, Galvani AP, Diuk-Wasser MA, 2012. Vector host-feeding preferences drive transmission of multi-host pathogens: west Nile virus as a model system. Proc $R$ Soc B Biol Sci 279: 925-933.

20. Spengler JR, Estrada-Peña A, 2018. Host preferences support the prominent role of Hyalomma ticks in the ecology of CrimeanCongo hemorrhagic fever. PLoS Negl Trop Dis 12: e0006248.

21. Randolph SE et al., 2008. Variable spikes in tick-borne encephalitis incidence in 2006 independent of variable tick abundance but related to weather. Parasit Vectors 1: 44.

22. Haggart DA, Davis EE, 1980. Ammonia-sensitive neurones on the first tarsi of the tick, Rhipicephalus sanguineus. J Insect Physiol 26: 517-523.

23. Estrada-Peña A, Jongejan F, 1999. Ticks feeding on humans: a review of records on human-biting Ixodoidea with special reference to pathogen transmission. Exp Appl Acarol 23: 685-715.

24. Socolovschi C, Raoult D, Parola P, 2009. Influence of temperature on the attachment of Rhipicephalus sanguineus ticks on rabbits. Clin Microbiol Infect 15: 326-327.

25. Carroll JF, 1999. Notes on responses of blacklegged ticks (Acari: ixodidae) to host urine. J Med Entomol 36: 212-215.

26. Uspensky I, 2019. Low air humidity increases aggressiveness of ixodid ticks (Acari: ixodidae) under high ambient temperatures (a preliminary hypothesis). Ticks Tick-borne Dis 10: 101274.

27. Papa A, Chaligiannis I, Xanthopoulou K, Papaioakim M, Papanastasiou S, Sotiraki S., 2010. Ticks parasitizing humans in Greece. Vector-borne Zoonotic Dis 11: 539-542.

28. Karl TR, Melillo JM, Peterson TC, Hassol SJ, eds., 2009. Global Climate Change Impacts in the United States. New York, NY: Cambridge University Press.

29. Black WC, Piesman J, 1994. Phylogeny of hard- and soft-tick taxa (Acari: ixodida) based on mitochondrial $16 \mathrm{~S}$ rDNA sequences. Proc Natl Acad Sci U S A 91: 10034-10038.

30. Dallas T, Foré S, 2013. Chemical attraction of Dermacentor variabilis ticks parasitic to Peromyscus leucopus based on host body mass and sex. Exp Appl Acarol 61: 243-250.

31. Mears S, Clark F, Greenwood M, Larsen KS, 2002. Host location, survival and fecundity of the Oriental rat flea Xenopsylla cheopis (Siphonaptera: pulicidae) in relation to black rat Rattus rattus (Rodentia: Muridae) host age and sex. Bull Entomol Res 92: 375-384.

32. Bates D, Machler M, Bolker B, Walker S, 2015. Fitting linear mixed-effects models using Ime4. J Stat Softw 67: 1-48.

33. Koch HG, Tuck MD, 1986. Molting and survival of the brown dog tick (Acari: ixodidae) under different temperatures and humidities. Ann Entomol Soc Am 79: 11-14.

34. Paz GF, Labruna MB, Leite RC, 2008. Drop off rhythm of Rhipicephalus sanguineus (Acari: ixodidae) of artificially infested dogs. Rev Bras Parasitol Veterinária 17: 139-144.

35. Harrison B, Engber B, Apperson C, 1997. Ticks (Acari: ixodida) uncommonly found biting humans in North Carolina. $J$ Vector Ecol 22: 6-12.

36. Nelson VA, 1969. Human Parasitism by the brown dog tick. J Econ Entomol 62: 710-712.

37. Gilot B, Laforge ML, Pichot J, Raoult D, 1990. Relationships between the Rhipicephalus sanguineus complex ecology and mediterranean spotted fever epidemiology in France. Eur $J$ Epidemiol 6: 357-362.

38. Mentz MB, Trombka M, Silva da GL, Silva CE, 2016. Rhipicephalus sanguineus (Acari: ixodidae) biting a human being in Porto Alegre city, Rio Grande do Sul, Brazil. Rev Inst Med Trop São Paulo 58: 35.

39. Rodríguez-Vivas RI, Apanaskevich DA, Ojeda-Chi MM, TrinidadMartínez I, Reyes-Novelo E, Esteve-Gassent MD, Pérez de León AA, 2016. Ticks collected from humans, domestic animals, and wildlife in Yucatan, Mexico. Vet Parasitol 215: 106-113.

40. Venzal JM, Guglielmone AA, Estrada Peña A, Cabrera PA, Castro O, 2003. Ticks (ixodida: ixodidae) parasitising humans in Uruguay. Ann Trop Med Parasitol 97: 769-772.

41. Bermúdez C, Sergio E, Castro A, Esser H, Liefting Y, García G, Miranda RJ, 2012. Ticks (ixodida) on humans from central Panama, Panama (2010-2011). Exp Appl Acarol 58: 81-88.

42. Carpenter TL, McMeans MC, McHugh CP, 1990. Additional instances of human parasitism by the brown dog tick (Acari: ixodidae). J Med Entomol 27: 1065-1066.

43. Dantas-Torres F, Latrofa MS, Annoscia G, Giannelli A, Parisi A, Otranto D, 2013. Morphological and genetic diversity of Rhipicephalus sanguineus sensu lato from the new and old worlds. Parasit Vectors 6: 213.

44. Nava S, Estrada-Peña A, Petney T, Beati L, Labruna MB, Szabó MPJ, Venzal JM, Mastropaolo M, Mangold AJ, Guglielmone AA, 2015. The taxonomic status of Rhipicephalus sanguineus (Latreille, 1806). Vet Parasitol 208: 2-8.

45. Arenas EE, Creus BF, Cueto FB, Porta FS, 1986. Climatic factors in resurgence of Mediterranean spotted fever. Lancet 327: 1333.

46. Raoult D, Dupont HT, Caraco P, Brouqui P, Drancourt M, Charrel C, 1992. Mediterranean spotted fever in Marseille: descriptive epidemiology and the influence of climatic factors. Eur J Epidemiol 8: 192-197.

47. Dantas-Torres F, 2010. Biology and ecology of the brown dog tick, Rhipicephalus sanguineus. Parasit Vectors 3: 26.

48. Traeger MS et al., 2015. Rocky Mountain spotted fever characterization and comparison to similar illnesses in a highly endemic area-Arizona, 2002-2011. Clin Infect Dis 60: 1650-1658.

49. Dalton MJ, Clarke MJ, Holman RC, Krebs JW, Fishbein DB, Olson JG, Childs JE, 1995. National surveillance for Rocky Mountain spotted fever, 1981-1992: epidemiologic summary and evaluation of risk factors for fatal outcome. Am J Trop Med Hyg 52: 405-413.

50. Holman RC, McQuiston JH, Haberling DL, Cheek JE, 2009. Increasing incidence of Rocky Mountain spotted fever among the American Indian population in the United States. Am J Trop Med Hyg 80: 601-605.

51. Raghavan RK, Goodin DG, Neises D, Anderson GA, Ganta RR, 2016. Hierarchical bayesian spatio-temporal analysis of climatic and socio-economic determinants of Rocky Mountain spotted fever. PLoS One 11: e0150180.

52. Arsnoe I, Tsao JI, Hickling GJ, 2019. Nymphal Ixodes scapularis questing behavior explains geographic variation in Lyme borreliosis risk in the eastern United States. Ticks Tick-borne Dis 10: 553-563.

53. Elizarov I, Vasiuta A, 1976. Distance orientation of the tick Ixodes persulcatus to the attractant factors of the prey. Parazitologiia 10: $136-141$.

54. Waladde SM, Rice MJ, 1982. The sensory basis of tick feeding behaviour. Obenchain FD, Galun R, eds. Physiology of Ticks. Elmsford, NY: Pergamon, 71-118.

55. Webb JP, 1979. Host-locating behavior of nymphal Ornithodoros concanensis (acarina: Argasidae). J Med Entomol 16: 437-447.

56. Perritt DW, Couger G, Barker RW, 1993. Computer-controlled olfactometer system for studying behavioral responses of ticks to carbon dioxide. J Med Entomol 30: 571-578.

57. de Oliveira Filho JG, Sarria ALF, Ferreira LL, Caulfield JC, Powers SJ, Pickett JA, de León AAP, Birkett MA, Borges LMF, 2016. Quantification of brown dog tick repellents, 2-hexanone and benzaldehyde, and release from tick-resistant beagles, Canis lupus familiaris. J Chromatogr B 1022: 64-69.

58. Louly CCB, Soares SF, Silveira DN, Neto OJS, Silva AC, Borges LMF, 2009. Differences in the susceptibility of two breeds of dogs, english cocker spaniel and beagle, to Rhipicephalus sanguineus (Acari: ixodidae). Int J Acarol 35: 25-32.

59. Gray JS, Dautel H, Estrada-Peña A, Kahl O, Lindgren E, 2009. Effects of climate change on ticks and tick-borne diseases in Europe. Interdiscip Perspect Infect Dis 2009: 593232. 